\title{
TRANSPOSITION AND EXPRESSION OF GFP GENE IN THE GENOME OF Vibrio harveyi TO MONITOR ITS ADHERENCE IN SHRIMP LARVAE
}

\author{
WIDANARNI $^{0}$, ANTONIUS SUWANTO^SUKENDA $^{1}{ }^{\prime}$, AND BIBIANA WIDIATI LAY ${ }^{3)}$ \\ " Faculty of Fisheries and Marine Science, Bogor Agricultural University, Bogor 16680, Indonesia \\ " Faculty of Science and Mathematics, Bogor Agricultural University, Bogor 16680. Indonesia \\ "Faculty of Veterinary Science, Bogor Agricultural University, Bogor 16680, Indonesia
}

\begin{abstract}
Expression of green fluorescent protein encoded by gfp gene in Vibrio harveyi was investigated to understand the ability of the gene as a molecular marker for adherence of this pathogenic Vibrio in shrimp larvae. The gfp gene was inserted into pl/ClSNot and pUTmini-Tn.') to generate a recombinant plasmid pWG02 and plVG03, respectively; which was transferred into the three isolates of $V$. han'eyi employing diparental mating. Recombinant $E$. coli carrying plVG02 and pWG03 resulted in green-fluorescent colonies and cells due to the production of GFP. However, all of mini-Tn.J, including mini-Tn.5-gfp were not successfully transferred to $V$. harveyi. Therefore, we used mini-Tn/fl (pLOFKm-gfp) for inserting of $g f p$ gene into $V$. han'eyi genome. Although we could obtain relatively high $\left(10^{\text {ss }}\right)$ transconjugans employing Tn/rt, only one of TnJO derived isolate of $V$. harveyi G3 (G3-Tn/flgfp) showed gfp expression and was further employed for adherence assay. Fluorescent G3-Tn70gfp cells could be observed inside the digestive tract of shrimp larvae and could be distinguished from Vibrio that naturally exist in shrimp larvae.
\end{abstract}

Key words: gfp gene, Vibrio han'eyi, gene expression, shrimp larvae, molecular marker

\section{INTRODUCTION}

Vibrio harveyi was identified as a causative agent of mass mortalities of shrimp larvae and were frequently associated with luminous Vibrio (Lavilla- Pitogo et al. । 990; Karunasagar et al. 1994; Ruangpan 1998, Suwanto et al. 1998). Luminescent vibriosis in shrimp larvae is characterized by lethargy, anorexia, muscle opacity, bacterial masses in the hemocoel, and luminosity of the larvae (Lavilla-Pitogo et al. 1990).

Electron microscopy observation has revealed that bacteria colonize the feeding apparatus, forming bacterial plaques in heavily infected larvae, therefore, it is highly probable that the mouth is the main entrance for colonization of inner tissues (Lavilla-Pitogo et al. 1990).

Pathogenicity assays based on Koch's Postulates (Madigan et al. 2003) were practically difficult to be conducted in shrimp larvae due to their relatively small size and lack of availability of Vibrio-free larvae (Widanarni and Suwanto 2000). Investigations into adherence and pathogenicity processes of this disease might

\footnotetext{
' Corresponding author: E-mail: asuvvanto@indo.net.id
} 
greatly facilitate if a visible marker could be introduced into the bacterial cells.

Pathogenic $V$. harveyi have observed their attachment to crustacean larvae by epifluorescence microscopy using 5-(4,6-dichorotriazin-2-yl) aminofluorescein (5-DTAF, D-16) as a marker (Soto-Rodriguez et al. 2003). One visible molecular marker which has extensively been used for studying bacterial activity in the environment is $g f p$, i.e. a gene encoding green fluorescent protein (GFP) from a jellyfish (Aequorea victoria) (Manning 1997). As a molecular gene marker, GFP has some advantages, such as no requirement for exogenous substrate or energy source for their visualization, sensitivity of detection, high stability, lack of toxicity, and no disturbance in cell function and growth (Josenhans et al. 1998; Ling et al. 2000).

GFP as a molecular marker has been used to demonstrate the mechanism of Edwardsiella tarda infection on epithelial cells of giant gouramy (Ling et al. 2000); and Pseudomonas plecoglosicida infection in ayu (Plecoglossus altivelis) (Sukenda and Wakabayashi 2001). GFP was also successfully used as a marker in lactic acid bacteria (Lactobacillus plantarum and $L$. lactis) to study the possibility of using the bacteria as live vaccine carriers (Geoffroy et al. 2000).

A broad host-range plasmid expressing $g f p$ gene (pWGOl) was constructed and has been successful to tag K harveyi (Widanarni et al. 2005). However, under non selective long- term experiments without antibiotic pressure, pWGOl was highly unstable. Therefore, transposon insertion may provide an alternative method to insert $g f p$ gene directly into the genomic DNA of $V$. harveyi in order to yield stable recombinants.

In this report, we describe the construction in Tn vector and expression of $V$. harveyi carrying gfp gene in the genomic DNAs to monitor its adherence in shrimp larvae.

\section{MATERIALS AND METHODS}

\section{Bacterial strains and plasmids}

Bacterial strains and plasmids used in this study and their relevant characteristics are described in Table 1. Escherichia coli and V. harveyi were grown in Luria Bertani (LB) medium at $37^{\circ} \mathrm{C}$ and Seawater Complete (SWC) medium at $28^{\circ} \mathrm{C}$, respectively. $\mathrm{LB}$ medium was made as previously described (Sambrook et al. 1989) and SWC medium contained 5 g bactopeptone, 1 g yeast extract, $3 \mathrm{ml}$ glycerol, $15 \mathrm{~g}$ agar, $750 \mathrm{ml}$ seawater, and $250 \mathrm{ml}$ distilled water.

\section{Plasmid construction and molecular techniques}

Recombinant plasmid pWG02 which has the lac promoter was constructed and used to drive the expression of $g f p$. The promoter and $g f p$ gene were isolated from pSKLOl using EcoRI sites and ligated into pUCISNot linearized with £coRI. The recombinant plasmid vector (pWG02) (Figure 1) was digested with Notl and then promoter and gfp gene were ligated into pUTmini-TnJ linearized with Noil resulting 
Transposition and expression of GFP gene - Widanami et al.

Table 1. Bacterial strains and plasmids used in this study

\begin{tabular}{|c|c|c|}
\hline $\begin{array}{l}\text { Bacterial strains } \\
\text { and plasmids }\end{array}$ & Relevant characteristic (s) & Source/Reference \\
\hline \multicolumn{3}{|l|}{ V. harveyi } \\
\hline MR5339 & Wild type & Maros Lab. collection \\
\hline G3 & Wild type & Gondol Lab. collection \\
\hline G7 & Wild type & Gondol Lab. collection \\
\hline G3-Tn $10 \mathrm{gfp}$ & G3::mini-TnloKmg $p, \mathrm{Km}^{\mathrm{R}}, \mathrm{gfp}^{+}$ & This study \\
\hline \multicolumn{3}{|l|}{ E. coli } \\
\hline DH5 $\alpha$ & F', lacZ? M15, recA1, hsdR17 & Sambrook et al. (1989) \\
\hline S17-1(גpir) & $\begin{array}{l}\text { Pro, Res, Mod }{ }^{+}, r e c A \text { integrated plasmid } \\
\text { RP4-Tc::Mu-Km:: } 7 n 7\end{array}$ & Herrero et al. (1990) \\
\hline SM10 (Apir) & $\begin{array}{l}\text { thi thr leu tonA lacY supE (Ipir) } \\
\text { recA::RP4-2-Tc::Mu Km }\end{array}$ & Stretton et al. (1998) \\
\hline Plasmid & & \\
\hline pSKL01 & $\mathrm{Gm}^{\mathrm{R}}, \mathrm{P}_{l a c}, \mathrm{gfp}^{+}$ & Sukenda and Wakabayashi (2001) \\
\hline pUC18Not & $\begin{array}{l}\text { Identical to pUC18 but with NotI- } \\
\text { polylinker of pUC18-NotI as MCS, Ap }{ }^{R}\end{array}$ & Herrero et al. (1990) \\
\hline $\begin{array}{l}\text { pUTmini-Tn } 5 \\
\mathrm{Sp} / \mathrm{Sm}\end{array}$ & $\begin{array}{l}\text { Tn } 5 \text { derivative of chromosomal } \\
\text { integration vector }\end{array}$ & de Lorenzo et al. (1990) \\
\hline pLOFKmg $f p$ & $\begin{array}{l}\text { pLOFKm with promoterless } g f p \text { cloned } \\
\text { upstream of } k a n, \mathrm{Km}^{\mathrm{R}}\end{array}$ & Stretton et al. (1998) \\
\hline pWG02 & $\begin{array}{l}\text { gfp gene of pSKL01 cloned into } \\
\text { pUC18Not, } \mathrm{Ap}^{\mathrm{R}}, \mathrm{gfp}^{+}\end{array}$ & This study \\
\hline pWG03 & $\begin{array}{l}g f p \text { gene of pWG02 cloned into } \\
\text { pUTmini-Tn } 5 \mathrm{Sp} / \mathrm{Sm}, \mathrm{Ap}^{\mathrm{R}}, \mathrm{gfp}^{+}, \mathrm{Sp} / \mathrm{Sm}^{\mathrm{R}}\end{array}$ & This study \\
\hline
\end{tabular}

in recombinant plasmid (pWGOS) (Figure 2). The recombinant plasmid vector was transformed into E. colt DH5a using a standard heat shock transformation (Sambrook et al. 1989) and the colonies carrying pWG02 and pWG03 were examined for green fluorescence under UV-transilluminator at $260 \mathrm{~nm}$ (Biometra Ti 1, Gottingen).

Plasmid extraction, restriction enzyme digestions, agarose gel electrophoresis, gel isolated DNA fragment purification, and ligation were carried out using standard methods (Sambrook et al. 1989), and following the manufacturer's instructions. Restriction endonucleases and other enzymes were obtained from New England Biolabs Inc (Beverly, MA, USA). 




Figure 1. Construction of $g f p$ carrier intermediate plasmid (pWG02)

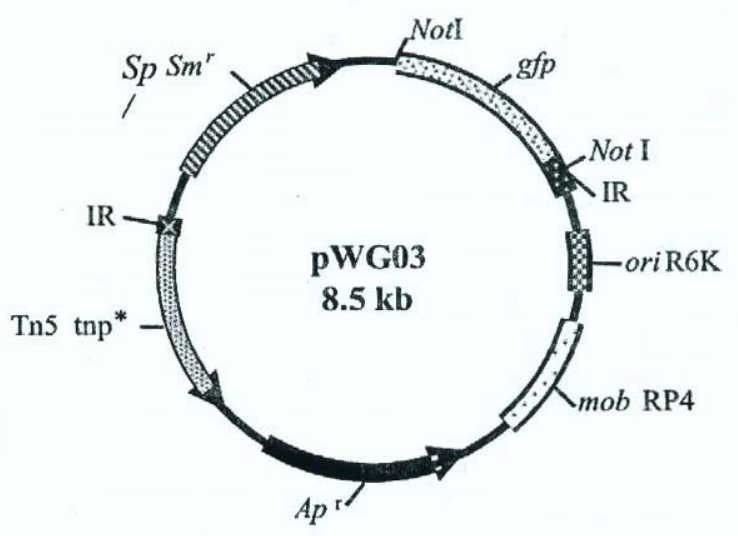

Figure 2. Construction of $g f p$ carrier plasmid for transposition based of $\operatorname{Tn} 5$

\section{Bacterial mating}

To transfer recombinant plasmid pWG03 harboring mini-Tn5gfp into $V$. harveyi we used diparental mating (Suwanto and Kaplan 1992). Escherichia coli DH5a (pWGOS) donors were grown overnight in LB medium supplemented with spectinomycin and streptomycin $(\mathrm{Sp} / \mathrm{Sm})$ 50 ugmT $^{1}$ at $37^{\circ} \mathrm{C}$; whereas $V$. harveyi recipients were grown in SWC medium at $28^{\circ} \mathrm{C}$. Each $1.5 \mathrm{ml}$ of the donor and recipient were pelleted in a micro-centrifuge at maximum speed for $1 \mathrm{~min}$, and then the cells were washed with $1.0 \mathrm{ml} 0.85 \% \mathrm{NaCl}$, re-centrifuged, and suspended in $40 \mathrm{ul}$ of LB medium before being spotted onto a filter ( $1 \mathrm{~cm}$ diameter; pore size $0.45 \mathrm{Urn}$; Millipore) on LB medium agar. The bacteria were allowed to conjugate at $28^{\circ} \mathrm{C}$ for 16 to 18 hours. At the end of the mating period, the filter containing the bacterial 
mixture was transferred into $1.5 \mathrm{ml}$ microfuge tube containing $0.8 \mathrm{ml}$ of $0.85 \% \mathrm{NaCl}$. The bacterial cells were suspended thoroughly by agitation on a vortex mixer.

The transconjugants were selected on Thiosulphate Citrate Bile Salt (TCBS, Oxoid) medium supplemented with Sp/Sm (50 jugm!"1 ). The selective medium TCBS was used to inhibit the growth of E. coli, while allowing $V$. harveyi transconjugants harboring TnJgfp (resistant to spectinomycin and streptomycin) to grow.

The same method was conducted to transfer recombinant plasmid pLOFKm-gfp (resistant to kanamycin) into $V$. harveyi and the transconjugants were selected on TCBS medium supplemented with kanamycin (100 (agml" $\left.{ }^{1}\right)$. Some of $V$. harveyi transconjugants were analyzed by Pulsed-Field Gel Electrophoresis (PFGE) with Notl restriction enzyme (Suwanto and Kaplan 1992; Widanarni and Suwanto 2000) to show the place of TnlOgfp inserted in the genomic of $V$. harveyi.

\section{GFP stability and pathogenicity assay}

Vibrio harveyi strains harboring $g / p$ both in the plasmid pWGOl (Widanarni et al. 2005) and in the genomic's DNA were grown overnight in SWC broth supplemented with kanamycin. Sequential propagation under non selective conditions were performed by inoculating with 1:100 $(\mathrm{v} / \mathrm{v})$ to assess $g f p$ existence by comparing duplicate colony counts on selective and non selective plates.

For pathogenicity assay, two groups with three duplicates of shrimp post-larvae ( $\left.\mathrm{PL}_{4}\right)$ were immersed for $30 \mathrm{~min}$ in $10^{6} \mathrm{CFUml}^{11}$ of gfp recombinants and wild type of $V$. harveyi (final concentration), respectively, and then placed in a $2 \mathrm{~L}$ shrimp rearing tank. A control group was immersed in sterile scawater. Daily survival rate of shrimp larvae for 5 days were recorded and compared with the control group.

\section{Adherence assay}

Samples of shrimp larvae from control and treatment groups were directly observed under a fluorescence microscope. Samples from dead shrimp larvae were also inoculated onto SWC plates containing kanamycin (100 figrnl"1) to show that the dead shrimp larvae were infected by recombinant $V$. harveyi.

\section{RESULTS AND DISCUSSION}

\section{GFP-containing plasmid construction}

The GFP-plasmid vector was constructed for molecular marker in $V$. harveyi. Two GFP vectors i.e. pWG02 and pWGOS, were constructed with lac promoter to drive the expression of gfp. Recombinant E. coli carrying pWG02 or pWG03 (mini-TnJgfp) resulted in green-fluorescent colonies and cells due to the production of GFP (Figure 3). However, all of mini-Tn5, including mini-TnJ-gfp was not successfully transferred to $V$. harveyi. The same results were observed by Stretton e? 

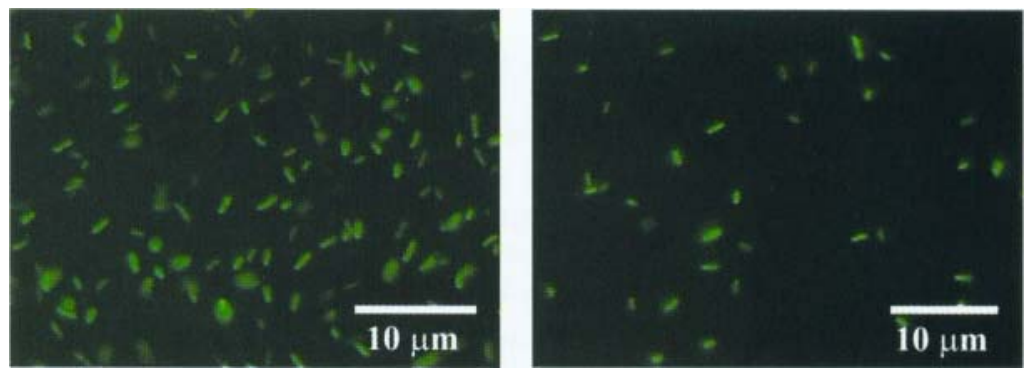

a

Figure 3. Fluorescence micrograph of (a) E. coli DH5a (pWG02) and (b) E. coli DHSct (pWG03)

al. (1998). Therefore, we used mini-Tn70 (pLOFKm-gfp) that has been constructed by Stretton et al. (1998) for inserting ofgfp gene into V. harveyi genome.

\section{Construction of $V$. harveyi gfp ${ }^{+}$employing mini-Tn/0 (pLOFKm-gfp)}

We could obtain relatively high transconjugants employing TnlO (Table 2). Pulsed-Field Gel Electrophoresis (PFGE) analysis of some $V$. harveyi transconjugants demonstrated that Tn70gfp was randomly inserted in the gcnomic V. harveyi G3 (Figure 4). However, only one of TnlO derived isolate of $V$. harveyi G3 (G3-Tn70gfp) resulted in green-fluorescent colonies and cells due to the expression of GFP and that fluorescence levels qualitatively was almost the same with G3 (pWGOl) (Figure 5). This result occurred due to the fact that $g f p$ in $p L O F K m g / p$ was constructed promoterless, so its expression depended on promoter strength in the insertion site within $V$. harveyi genome.

Table 2. Frequency of $\operatorname{Tn} l 0$ based-gfp transfer to $V$. harveyi strains

\begin{tabular}{cccc}
\hline Recipients & $\begin{array}{c}\text { Number of } \\
\text { transconjugants }\end{array}$ & $\begin{array}{c}\text { Frequency (transconjugants/ } \\
\text { recipients) }\end{array}$ & $\begin{array}{c}\text { Number of } \\
\text { green } \\
\text { colonies }\end{array}$ \\
\hline V. harveyi MR5339 & 378 & $2.3 \times 10^{-7}$ & - \\
V. harveyi G3 & 924 & $5.5 \times 10^{-7}$ & 1 \\
V. harveyi G7 & 154 & $9.2 \times 10^{-8}$ & - \\
\hline
\end{tabular}

\section{GFP stability and pathogenicity assay}

Colonies of $V$, harveyi G3 (G3-Tn70gfp) that were grown on media with or without antibiotic exhibited uniform fluorescence appearance. This was not the case 


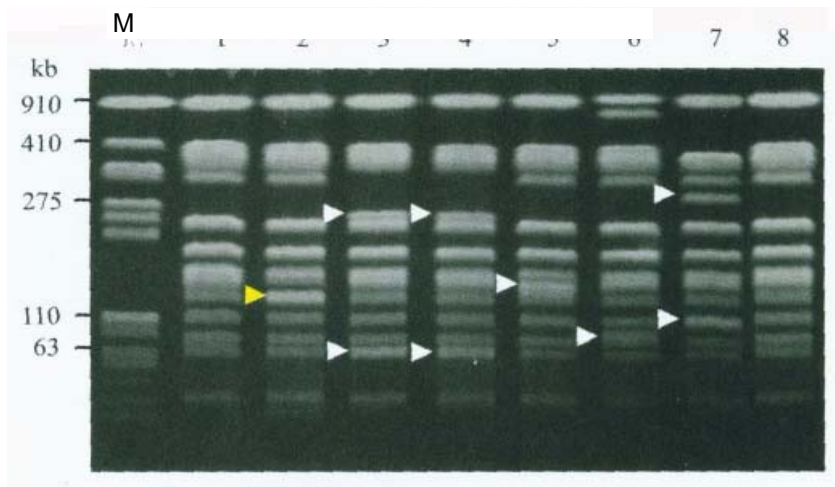

Figure 4. PFGE profiles of genomic DNA of $V$. harveyi G3 (Lane M: Axel-digested genotnic DNA of $R$. sphaeroides 2.4.1 as a molecular size marker (Suwanto and Kaplan 19 89). Lane 1 and 8: G3 wild type, Lane 2: G3 Tn/flgfp $\left(\mathrm{Km}^{\mathrm{R}}\right.$ and showed gfp expression), Lane 3 -7: mutants $03\left(\mathrm{Km}^{\mathrm{K}}\right)$

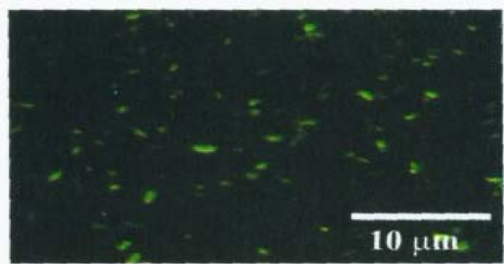

a

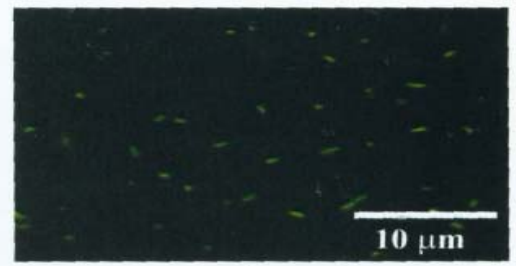

b

Figure 5. Fluorescence micrograph of (a) V. harveyi G3 (pWGOi) and (b) G3-Tn/Ogfp

for $V$. harveyi G3 (pWGOl). Their colonies grown on antibiotic-containing media exhibited uniform fluorescence appearance, whereas those grown on media without antibiotic showed mixture of fluorescent and non fluorescent colonies which might indicate plasmid loss. The stability of the GFP on $V$. harveyi G3 both in plasmid and in the genomic's DNA were investigated during sequential propagation in the absence of antibiotic selection for five successive days. Under nonselective long-term experiments without antibiotic pressure, pWGOl was highly unstable but Tn/0gfp was stably maintained in V. harveyi G3 strain (Figure 6). Insertion of Tn70gfp also did not show alteration in G3 pathogenicity to shrimp larvae (Figure 7), so that it was further employed for adherence assay.

\section{Adherence assay}

Sample from dead shrimp larvae showed that the dead larvae were infected by $V$. harveyi. Vibrio harveyi G3-Tn/0gfp could be isolated from dead shrimp larvae 


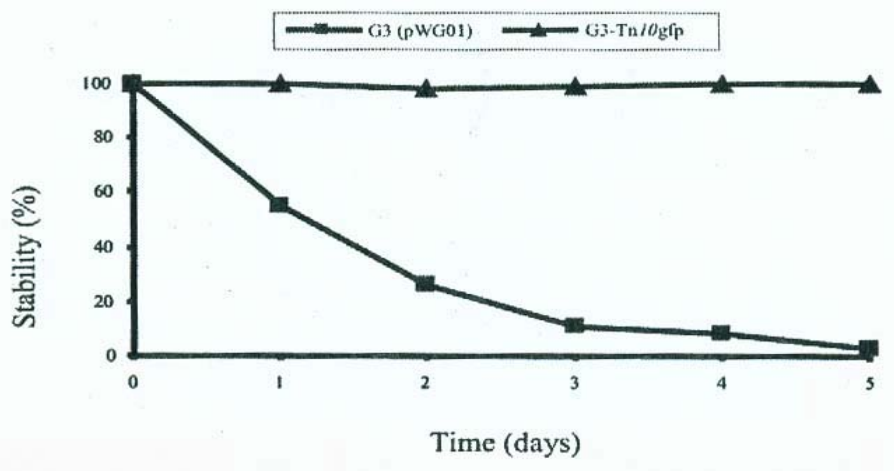

Figure 6. Stability of $g f p$ in $V$. harveyi G3 (pWG01) and G3-Tn10gfp

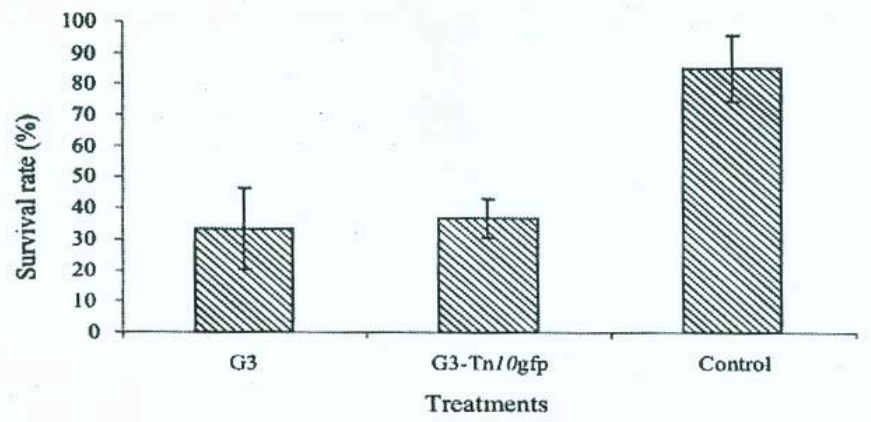

Figure 7. Survival rate of shrimp larvae on pathogen challenge assay of $V$. harveyi G3 and G3-Tn $10 \mathrm{gfp}$

placed on TCBS+Km media and fluorescent G3-Tn70gfp could also be observed directly in the carcasses of dead larvae. Fluorescent G3-TnJOgfp cells were observed in the oral region at 15-30 min after inoculation and could be observed inside the digestive tract at 2-3 h (Figure 8V The concentration of $V$. harveyi G3-TnlOgfp used in this study was 10 CFUml". Soto-Rodriquez et al. (2003) reported that $10^{5} \mathrm{CFUml}^{\prime \prime 1} \mathrm{~V}$. harveyi labeled with 5-(4,6-dichlorotriazin-2-yl) aminofluorescein (5-DTAF, D-16) could be observed in the oral region of Litopenaeus vannamei mysis at 0 and $2 \mathrm{~h}$ after ingestion. After $4 \mathrm{~h}$ inoculation, individual cells could already be seen inside the middle intestine, and at 18 or $24 \mathrm{~h}$, the fluorescent $V$. harveyi were observed throughout the intestinal tract. When presented at higher densities of bacterial cells (exclusively), fluorescent $V$. harveyi could be easily observed along all regions of zoea digestive tracts after 30 min (Soto-Rodriquez et al. 2003). 

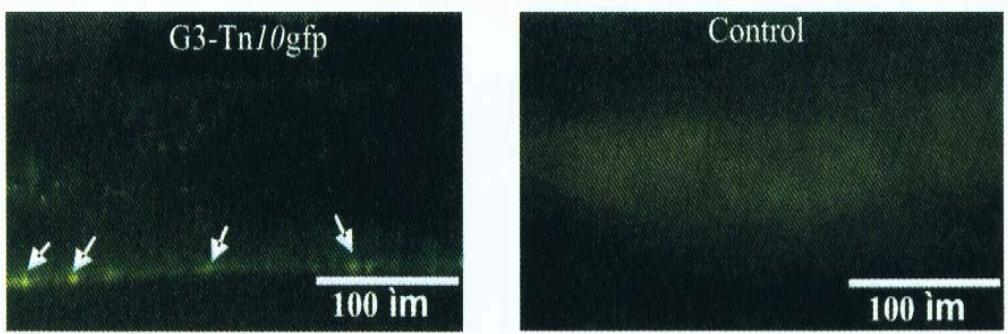

Figure 8. Observation of $V$. harveyi G3-Tn/0gfp in the digestive tract of shrimp larvae

\section{CONCLUSIONS}

Recombinant $V$. harveyi harboring $g f p$ both in plasmid pWGOl and in the genomic DNAs produced green-fluorescent cells. However, Tn7(?gfp was stably maintained in the genomic $V$. harveyi so that it could be used to monitor adherence and pathogenicity of $V$. harveyi in shrimp larvae.

\section{ACKNOWLEDGMENTS}

This work was supported by DIP-Funded Research of SEAMEO-B1OTROP (2000-2002) and International Foundation for Science grant (IPS, A/2207-2) to AS.

\section{REFERENCES}

Geoffrey M.C., Guyard C., Quatannens B., Pavan S., Lange M. and A. Mercenier. 2000. Use of green fluorescent protein to tag lactic acid bacterium strains under development as live vaccine vectors. Appl. Environ. Microbiol., 66: 383-391.

Herrero M., de Lorenzo V. and K.N. Timmis. 1990. Transposon vectors containing non-antibiotic resistance selection marker for cloning and stable chromosomal insertion of foreign genes in Gram negative bacteria. J. Bacteriol., 172:6557-6567.

Josenhans C., Friedrich S. and S. Suerbaum. 1998. Green fluorescent protein as a novel marker and reporter system in Helicobacter sp. FEMS Microbiol. Lett., 161:263-273.

Karunasagar I., Pai R, Malathi G.R. and I. Karunasagar. 1994. Mass mortality of Penaeus monodon larvae due to antibioticresistant Vibrio harveyi infectioa Aquaculture, 128:203-209.

Lavilla-Pitogo C.R., Baticados M.C.L., Cruz-Lacierda EJR. and L.D. De la Pena. 1990. Occurrence of luminous bacterial diseases ofPenaeus monodon larvae in the Philippines. Aquaculture, 91:1-13.

Ling S.H.M., Wang X.H., Xie L, Lim T.M. and K.Y. Leung. 2000. Use of fluorescent protein (GFP) to study the invasion pathways ofEdwardsiella tarda in in vivo and in vitro fish models. Microbiol., 146:7-19.

Madigan M.T., Martinko J.M. and J. Parker. 2003. Brock Biology of Microorganisms. Prentice-Hall Pearson Education inc. USA., p. 12-13. 
Manning E. 1997. Glow fish: an unusual glowing molecule from jelly fish is helping to illuminate cellular events. Bioscience, 47:135-138.

Ruangpan L. 1998. Luminous bacteria associated with shrimp mortality. In Flegel TW (ed) Advances in Shrimp Biotechnology. National Center for Genetic Engineering and Biotechnology, Bangkok.

Sambrook J.. Fritsch E.F. and T. Maniatis. 1989. Molecular Cloning. Cold Spring Harbor Laboratory Press. New York. USA.

Soto-Rodriguez S.A., Simoes N., Jones D.A., Roque A. and B. Gomez-Gil . 2003. Assessment of fluorescent-labeled bacteria for evaluation of in vivo uptake of bacteria (Vibrio spp.) by crustacean larvae. J. Microbiol. Methods, 52:101114.

Stretton S., Techkamjanaruk S., McLennan A.M. and A.E. Goodman. 1998. Use of green fluorescent protein to tag and investigate gene expression in marine bacteria. Appl. Environ. Microbiol., 64:2554-2559.

Sukenda and H. Wakabayashi. 2001. Adherence and infectivity of green fluorescent protein-labeled Pseudomonasplecog/ossicida toayu (Plecoglossus altivelis). FishPathol., 36:161-167.

Suwanto A. and S. Kaplan. 1989. Physical and genetic mapping of the Rhodobacter sphaeroides 2.4.1 genome: genome size, fragment identification, and gene localization. J. Bacteriol., 171:5840-5849.

Suwanto A. and S. Kaplan. 1992. A self-transmissible, narrow-host-range endogenous plasmid of Rhodobacter sphaeroides 2.4.1: physical structure, incompatibility determinants, origin of replication, and transfer functions. J. Bacteriol., 174:1124-1134.

Suwanto A., Yuhana M. , Herawaty E. and S.L. Angka. 1998. Genetic diversity of luminous Vibrio isolated from shrimp larvae. In Flegel TW (ed) Advances in Shrimp Biotechnology. National Center for Genetic Engineering and Biotechnology, Bangkok.

Widanami and A. Suwanto. 2000. Genetic diversity of ampicillin resistant Vibrio isolated from various stages of shrimp larvae development. BIOTROPIA, 15:36-47.

Widanami, Suwanto A., Sukenda and B.W. Lay. 2005. Construction of recombinant Vibrio hai-veyi to study its adherence in shrimp larvae. In P Walker R, J Lester, MG Bondad-Reantaso (eds). Diseases in Asian Aquaculture V, p. 465-474. Fish Health Section, Asian Fisheries Society, Manila. 